\title{
In vitro effects of alcohol-containing mouthwashes on human enamel and restorative materials
}

\section{José Eduardo Pelizon PELINO(a) Alan PASSERO(b) \\ Airton Abrahao MARTIN(c) \\ Christine Ann CHARLES(a)}

\footnotetext{
(a) Johnson \& Johnson Consumer Companies, São Paulo, SP, Brazil.

(b)Johnson \& Johnson Consumer, Inc., São José dos Campos, SP, Brazil.

(c) Universidade do Vale do Paraíba - Univap, Physics Institute, São José dos Campos, SP, Brazil.
}

Declaration of Interest: Christine Ann Charles was employed by Johnson \& Johnson at the time of the study.

\begin{abstract}
Corresponding Author:
José Eduardo Pelizon Pelino

E-mail: jpelino@its.jni.com
\end{abstract}

ht1ps://doi.org/10.1590/1807-3107bor-2018.vol32.0025

Submitted: August 29, 2017

Accepted for publication: January 26, 2018

Last revision: February 21, 2018
Abstract: The objective of this study was to evaluate the in vitro effects, including surface morphological characteristics and chemical elemental properties, of different mouthwash formulations on enamel and dental restorative materials, simulating up to 6 months of daily use. Human enamel samples, hydroxyapatite, composite resin, and ceramic surfaces were exposed to 3 different mouthwashes according to label directions - Listerine ${ }^{\circledast}$ Cool Mint ${ }^{\circledast}$, Listerine ${ }^{\circledR}$ Total Care, and Listerine ${ }^{\circledR}$ Whitening - versus control (hydroalcohol solution) to simulate daily use for up to 6 months. The samples were analyzed using scanning electron microscopy (SEM), infrared spectrophotometry ( $\mu$-Fourier transform infrared microscopy), energy-dispersive X-ray (EDX) spectroscopy, and color analysis before and after exposure. No relevant changes were observed in the morphological characteristics of the surfaces using SEM techniques. The physical and chemical aspects of the enamel surfaces were evaluated using mid-infrared spectroscopy, and EDX fluorescence was used to evaluate the elemental aspects of each surface. There was no variation in the relative concentrations of calcium and phosphorus in enamel, silicon and barium in composite resin, and silicon and aluminum in the ceramic material before and after treatment. No relevant changes were detected in the biochemical and color properties of any specimen, except with Listerine ${ }^{\circledast}$ Whitening mouthwash, which demonstrated a whitening effect on enamel surfaces. Long-term exposure to low $\mathrm{pH}$, alcoholcontaining, and peroxide-containing mouthwash formulations caused no ultra-structural or chemical elemental changes in human enamel or dental restorative materials in vitro.

Keywords: Mouthwashes; Composite Resins; Hydroxyapatites; Ceramics; Microscopy, Electron, Scanning.

\section{Introduction}

Biofilm control is paramount in preventive dentistry and directly reflects the oral health of individuals. Various methods, such as mechanical procedures, chemical agents, or a combination of both, can be used to achieve adequate biofilm control. ${ }^{1,2}$ Pathogenic microorganisms present in the biofilm are a contributing factor to dental caries and periodontal disease, suggesting that removal of biofilm can be essential to the prevention of such conditions. Mechanical control of the biofilm continues to be important 
in preventing periodontal diseases and maintaining oral health. In addition, the use of mouthwashes has shown substantial ability for biofilm control.

The prevention of oral diseases and the promotion of oral health must be comprehensively addressed to control the initiation and development of dental caries and periodontal diseases, which have been shown to compromise both oral and general health. The Council of Scientific Affairs (American Dental Association [ADA]) has adopted a program to evaluate the efficacy of various agents used to control gingivitis via biofilm control. According to the criteria set forth, such agents must be evaluated for over 6 months, by placebocontrolled clinical trials and demonstrate a significant improvement in gingival health when compared to a placebo group. To date, 2 mouthwash agents have been approved for use by the ADA to control dental plaque and gingivitis: chlorhexidine and a fixed combination of essential oils (eucalyptol [0.092\%], menthol [0.042\%], methyl salicylate [0.060\%], and thymol [0.064\%]).

The prevalence of gingivitis and periodontal diseases is high, even in young people. ${ }^{3,4}$ For a considerable proportion of individuals, mechanical methods alone are not sufficient to maintain gingival health and prevent the occurrence, recurrence or progression of periodontal diseases. The addition of chemotherapeutic agents for biofilm control can augment the effect of mechanical methods and help prevent the development of periodontal diseases. ${ }^{1,5,6}$ Though essential oil-containing mouthwashes have been proven safe and efficacious in daily use for over 100 years, ${ }^{7}$ there are still safety concerns regarding tooth enamel and dental restorative materials because of their low $\mathrm{pH}(<5.5),{ }^{8,9}$ the presence of peroxide (for tooth whitening), and alcohol ${ }^{10}$ (used as a solubilizer and preservative). ${ }^{10}$ Therefore, this in vitro study aimed to compare the effect of 3 different mouthwash formulations on human enamel, commonly used dental restorative materials, and hydroxyapatite, over a simulated 3- to 6-month period of daily use.

\section{Methodology}

Human teeth, comprising premolars and third molars that were extracted due to orthodontic or surgical indications, were obtained from the School of Dentistry at the University of Taubaté. Teeth with abnormal features such as cracks, cavities, and fillings close to the testing area were excluded. In total, 20 teeth were used in this study, and the study protocol was approved by the ethics committee of the School of Dentistry at the University of Taubaté (Protocol\# 388/10).

\section{Teeth and specimen preparation}

The crown of each tooth was separated from the root, and 4 samples from each crown surface (buccal, lingual, mesial, and distal), measuring $4.0 \pm 0.2 \mathrm{~mm}$ $\times 4.0 \pm 0.2 \mathrm{~mm}$ with a thickness of $6.0 \pm 0.2 \mathrm{~mm}$, were obtained. The hydroxyapatite disks measured $5.0 \pm$ $0.2 \mathrm{~mm}$ (diameter) $\times 2.0 \pm 0.2 \mathrm{~mm}$ (thickness) and were white in color with no cracks (Lot \# 080109-5 mm; Hitemco Medical, Old Bethpage, USA). Both the composite resin samples (Tetric N-Ceran, Ivoclar Vivadent; Shade A3.5, K42776, Exp. 2011-14), light cured using LEC Prime (WL SN/528; MM Optics Code: 10.02307), and the feldspathic ceramic samples (shade A2) measured $6.6 \pm 0.2 \mathrm{~mm}$ (diameter) $\times 1.40$ $\pm 0.2 \mathrm{~mm}$ (thickness). Irregular or stained samples were discarded. The selected samples were rinsed using distilled water and stored in artificial saliva for $\leq 7$ days ( $40 \mathrm{~mL}$ of complete saliva, Lot \# 32699, Northeast Laboratory, USA; Lab-Lemco powder, proteose peptone, yeast extract, type II hog gastric mucin, sodium chloride, calcium chloride, purified water, and $10 \%$ urea solution) at room temperature until used for treatment.

\section{Surfaces evaluation by scanning electron microscopy}

High-resolution $100 \times$ and 3,000× images were acquired using a scanning electron microscope (SEM) and formatted virtually by transcription of the electron beam path between the sample and the condenser lenses of the microscope, forming a 3-dimensional image that was used to evaluate the surface morphology. The samples were attached to the SEM stubs and sputtered with a mix of gold and palladium. The morphology of the samples was determined using the EVO LS SEM (Carl Zeiss SMT $\mathrm{GmbH}$, Germany), operated at $20 \mathrm{kV}$ under high vacuum at a working distance of $14-15 \mathrm{~mm}$. 


\section{Mineral quantification by energy- dispersive x-ray fluorescence spectrometry}

Energy-dispersive X-ray (EDX) spectroscopy is an analytical technique used for elemental analysis, such as observation of demineralization in tooth surfaces. Semi-quantitative elemental analyses of the samples were performed using an energy-dispersive micro-X-ray fluorescence spectrometer ( $\mu$-EDX 1300, Shimadzu, Kyoto, Japan), equipped with a rhodium $\mathrm{X}$-ray tube and a liquid nitrogen-cooled $\mathrm{Si}(\mathrm{Li})$ detector. The equipment was coupled to a computer system for data acquisition and processing (Shimadzu $\mu$-EDX MP ver. 1.03). The voltage was set at $15 \mathrm{kV}$ with an incident beam diameter of $50 \mu \mathrm{m}$. Data were obtained by scanning $1.0 \times 1.0 \mathrm{~mm}$ sections of each specimen. Semi-quantitative elemental analyses of calcium (Ca) and phosphorus $(\mathrm{P})$ concentrations in enamel and hydroxyapatite, silica (Si), and barium (Ba) concentrations in composite resins. In ceramic samples, Si and aluminum (Al) concentrations were performed using the $\mu$-EDX 1300, operating at 50 $\mathrm{kV}$ with an incident beam diameter of $50 \mu \mathrm{m}$. Line mapping was performed using $40 \times 1$ points with a $10-\mu \mathrm{m}$ step along each sample.

\section{Infrared microscopy}

The Fourier transform-Infrared Microscopy (FT-IRM) technique enables detailed observation of the surface through the reflection of the produced radiance, which is directly related to the observed chemical structure of the surfaces. Spectral FT-IR data were obtained using the Spectrum Spotlight 400 device (Perkin-Elmer, Wellesley, USA), equipped with a microscope fitted with both white light and infrared optics and a liquid nitrogen-cooled mercury-cadmium telluride (MCT) detector. Spectra were collected at a $2 \mathrm{~cm}^{-1}$ resolution, in the range of $4000-750 \mathrm{~cm}^{-1}$ from 64 scans by using a reflectance technique with a point mode. The aperture size was $50 \times 50 \mu \mathrm{m}$, and the spectra were baseline corrected, normalized, and transformed to the absorbance spectra.

\section{Colorimetric analysis}

The color measurements were determined by using a Minolta colorimeter (Konica Minolta model CR-400) and analyzing CIE L*a*b* parameters. A white-colored plate was used as a standard for calibration and as a background for color measurements. CIE L*a*b* values were evaluated based on reflectance measurements, where L* indicates luminosity, a* indicates redness, and $b^{*}$ indicates yellowness. Three analyses were recorded before and after sample immersion.

\section{Treatment}

Table 1 presents the 4 treatment regimens that were randomly assigned to samples. Four different samples were immersed in 3 different mouthwashes as follows: Essential oils mouthwash (EO; LISTERINE ${ }^{\circledR}$ Cool Mint $\left.{ }^{\circledR}\right)$, essential oils + fluoride (100 ppm) + zinc chloride mouthwash (EOFZC; LISTERINE ${ }^{\circledR}$ Total Care), 2.0\% hydrogen peroxide mouthwash (HP; LISTERINE ${ }^{\circledR}$ Whitening Original Pre-brush Rinse), and 21.6\% hydroalcohol control solution $(\mathrm{H})$. Table 2 describes the mouthwashes used in this study. All samples were stored in artificial saliva between treatments and after each period of analysis: baseline, 1, and 3 months for HP, and baseline, 3, and 6 months for EO and EOFZC. Samples were immersed in the EO and EOFZC mouthwashes for

Table 1. Specimen distribution.

\begin{tabular}{|c|c|c|c|c|}
\hline Groups & $\begin{array}{l}\text { Enamel }(E) \\
(n=5)\end{array}$ & $\begin{array}{l}\text { Hydroxyapatite }(\mathrm{Ha}) \\
\quad(\mathrm{n}=5)\end{array}$ & $\begin{array}{l}\text { Composite Resin (CR) } \\
(n=5)\end{array}$ & $\begin{array}{l}\text { Ceramic (C) } \\
(\mathrm{n}=5)\end{array}$ \\
\hline Group 1 - Essential Oils (EO) Mouthwash $(n=20)$ & EO El & $\mathrm{EO} \mathrm{Hal}$ & EO CR 1 & $\mathrm{EOCl}$ \\
\hline $\begin{array}{l}\text { Group } 2 \text { - Essential Oils }+ \text { Fluoride }+ \text { Zinc Chloride } \\
\text { (EOFZC) Mouthwash }(n=20)\end{array}$ & EOFZC E2 & EOFZC Ha2 & EOFZC CR2 & EOFZC C2 \\
\hline $\begin{array}{l}\text { Group } 3-2.0 \% \text { Hydrogen Peroxide (HP) Mouthwash } \\
(\mathrm{n}=20)\end{array}$ & HP E3 & $\mathrm{HP} \mathrm{Ha} 3$ & HP CR3 & HP C3 \\
\hline $\begin{array}{l}\text { Group } 4 \text { - Hydroalcohol Control Solution }(\mathrm{H}) \\
(\mathrm{n}=20)\end{array}$ & HE4 & $\mathrm{HHa} 4$ & H CR4 & $\mathrm{HC} 4$ \\
\hline
\end{tabular}


3 cycles of 30 minutes each with three 30 -minute intervals to simulate 3 months of daily use, and in 3 cycles of 60 minutes each with three 60 -minute intervals to simulate 6 months of daily use. The total immersion time for simulating 3 months of daily use was 90 minutes. Similarly, the total immersion time for 6 months of daily use was 180 minutes (Table 3). The samples were immersed in the HP mouthwash in 3 cycles of 10 minutes each with three 10-minute intervals to simulate 1 month of daily use, and in 3 cycles of 30 minutes each with three 30-minute intervals to simulate 3 months of daily use. The total immersion time for simulating 1 month of daily use was 30 minutes. The total immersion time for 3 months of daily use was 90 minutes. The immersion time was based on a pilot study that aimed to simulate clinical use (Table 4).

\section{Data analysis and statistical methods}

Analyses were based on data from all samples, comprising human enamel, hydroxyapatite, composite resin, and ceramic samples treated with the study mouthwashes or control $(\mathrm{H})$ solution without any major protocol violations. A 95\% confidence interval of the least square (LS) means and Student's $t$ test were used to compare the means obtained from the EDX and CIE L*a*b* color analyses.

For the primary analysis, use of EO, EOFZC, and $\mathrm{HP}$ mouthwashes and control $(\mathrm{H})$ solution was assessed according to the following aspects:

a. Possible overall morphological changes after an equivalent period of baseline and 3 and 6 months of treatment with EO and EOFZC compared with the initial morphological values of the tested samples.

Table 2. Ingredients and active components of the tested mouthwashes.

\begin{tabular}{|c|c|c|c|}
\hline Active components & Brand name & Manufacturer & Ingredients \\
\hline Essential Oils & LISTERINE ${ }^{\circledR}$ Cool Mint & $\begin{array}{l}\text { Johnson \& Johnson, São } \\
\text { José dos Campos, SP, Brazil }\end{array}$ & $\begin{array}{l}\text { Water, ethanol, menthol, eucalyptol, thymol, methyl } \\
\text { salicylate, benzoic acid, poloxamer } 407 \text {, and flavor }\end{array}$ \\
\hline $\begin{array}{l}\text { Essential Oils }+ \text { Fluoride }+ \\
\text { Zinc Chloride }\end{array}$ & LISTERINE ${ }^{\circledR}$ Total Care & $\begin{array}{l}\text { Johnson \& Johnson, São } \\
\text { José dos Campos, SP, Brazil }\end{array}$ & $\begin{array}{l}\text { Water, ethanol, menthol, eucalyptol, thymol, } \\
\text { methyl salicylate, benzoic acid, poloxamer 407, } \\
\text { fluoride, zinc chloride, and flavor }\end{array}$ \\
\hline 2.0\% Hydrogen Peroxide & $\begin{array}{l}\text { LISTERINE }{ }^{\circledR} \text { Whitening } \\
\text { Original Pre-brush Rinse }\end{array}$ & $\begin{array}{l}\text { Johnson \& Johnson, São } \\
\text { José dos Campos, SP, Brazil }\end{array}$ & $\begin{array}{l}\text { Water, hydrogen peroxide, ethanol, menthol, } \\
\text { eucalyptol, benzoic acid, poloxamer 407, and flavor }\end{array}$ \\
\hline \multirow[t]{2}{*}{ NA } & Hydroalcohol Solution & $\begin{array}{l}\text { Johnson \& Johnson, São } \\
\text { José dos Campos, SP, Brazil }\end{array}$ & Water and ethanol \\
\hline & (21.6\% alcohol) & & \\
\hline
\end{tabular}

Table 3. Immersion time per group for the essential oils (EO) and essential oils + fluoride + zinc chloride (EOFZC) mouthwashes.

\begin{tabular}{|c|c|c|c|c|c|}
\hline $\begin{array}{l}\mathrm{G} 1 / \mathrm{G} 2, \\
\text { minutes }\end{array}$ & $\mathrm{Al}$ & $\begin{array}{c}3 \\
\text { months }\end{array}$ & $\mathrm{A} 2$ & $\begin{array}{c}6 \\
\text { months }\end{array}$ & A3 \\
\hline IP & \multirow{7}{*}{$\begin{array}{l}\text { Baseline / } \\
\text { Analysis } 1\end{array}$} & 30 & & 60 & \\
\hline INT & & 30 & & 60 & \\
\hline IP & & 30 & & 60 & \\
\hline INT & & 30 & Analysis 2 & 60 & Analysis 3 \\
\hline IP & & 30 & & 60 & \\
\hline INT & & 30 & & 60 & \\
\hline TIP & & 90 & & 180 & \\
\hline
\end{tabular}

Table 4. Immersion time per group for the $2.0 \%$ hydrogen peroxide $(\mathrm{HP})$ mouthwash and control solution $(\mathrm{H})$.

\begin{tabular}{|c|c|c|c|c|c|}
\hline $\begin{array}{l}\text { G3/G4, } \\
\text { minutes }\end{array}$ & $\mathrm{Al}$ & 1 month & A2 & 3 months & A3 \\
\hline IP & & 10 & & 30 & \\
\hline INT & & 10 & & 30 & \\
\hline IP & & 10 & & 30 & \\
\hline INT & $\begin{array}{l}\text { Baseline / } \\
\text { Analysis ] }\end{array}$ & 10 & Analysis 2 & 30 & Analysis 3 \\
\hline IP & & 10 & & 30 & \\
\hline INT & & 10 & & 30 & \\
\hline TIP & & 30 & & 90 & \\
\hline
\end{tabular}


b. Possible overall chemical changes after an equivalent period of baseline and 3 and 6 months of treatment with EO and EOFZC compared with the initial chemical values of the tested samples.

c. Possible overall $L^{*} a^{*} b^{*}$ changes after an equivalent period of baseline and 3 and 6 months of treatment with EO and EOFZC compared with the initial $L^{*} a^{*} b^{*}$ values of the tested samples.

d. Possible overall morphological changes after an equivalent period of baseline and 1 and 3 months of treatment with HP compared with the initial morphological values of the tested samples.

e. Possible overall chemical changes after an equivalent period of baseline and 1 and 3 months of treatment with HP compared with the initial chemical values of the tested samples.

f. Possible overall $L^{*} a^{*} b^{*}$ changes after an equivalent period of baseline and 1 and 3 months of treatment with HP compared with the initial $L^{*} a^{*} b^{*}$ values of the tested samples.

The regression models were adjusted for emphasis in effect screening and the analyses were performed using the JMP statistical software version 12 with the significance level set at $\alpha=0.05$. Differences with p-values of $<0.05$ were considered significant. Concerning colorimetric analysis, $\Delta \mathrm{E}$ values $<3$ were considered not clinically relevant since they are weakly perceptible to the eye.

\section{Results}

\section{Scanning electron microscopy}

No changes were observed in dental enamel, hydroxyapatite, and composite resin surfaces after immersion in the EO and EOFZC mouthwashes as well as the control solution. A superficial change was observed on the enamel surface at 1 month after using the HP mouthwash, which was reversed after 3 months of daily use. A trend toward change in erosion without demineralization was observed after exposure to the HP mouthwash and control solution. Most of the changes were regular circular erosions, measuring 2 to $3 \mu \mathrm{m}$, observed to a considerable extent on the ceramic samples with respect to the HP mouthwash, and regular circular erosions, measuring 1 to $2 \mu \mathrm{m}$, at 1 month and $>10 \mu \mathrm{m}$ at 3 months with the control solution. There was no change on the ceramic samples after exposure to the EO mouthwash. The ceramic samples exposed to the EOFZC mouthwash showed mild changes on the surface after 3 months, but showed normal appearance after 6 months of exposure (Figures 1-5).

\section{Energy-dispersive X-ray}

No demineralization was observed on the enamel and hydroxyapatite surfaces tested during any examination period. The EDX analysis showed that $\mathrm{Ca}$ and $\mathrm{P}$ concentrations remained the same before and after exposure to mouthwashes. Similar results were observed for composite resin and ceramic surfaces. Moreover, Si and Ba concentrations remained the same for composite resin surfaces and $\mathrm{Si}$ and $\mathrm{Al}$ concentrations remained the same for ceramic surfaces before and after exposure to mouthwashes (Table 5).

\section{FT-IRM}

A detailed observation of the surfaces was recorded using infrared microscopy, through the reflection of radiance to evaluate not only the visible image but also the image formed by infrared spectrum (chemical imaging). The spectra obtained from the studied surfaces corresponded to the pattern spectra of the enamel, ceramic, and composite resin; no change was observed even after simulating 6 months of daily use.

\section{Colorimetric analysis}

The color measurements (Konica Minolta model CR-400) were based on the CIE L*a* b* measurements. Luminosity $\left(\mathrm{L}^{*}\right)$ /coordinate $\mathrm{a}^{*}$ (variation between red and green)/coordinate $b^{*}$ (variation between yellow and blue) were determined. No change was detected in the color properties of any specimen, except for the HP rinse, which had a whitening effect on the enamel surface (Table 6).

\section{Discussion}

The results showed that simulated long-term exposure (up to 6 months) to alcohol-containing mouthwashes (EO, EOFZC, and HP) caused no morphological, ultra-structural, or biochemical change 

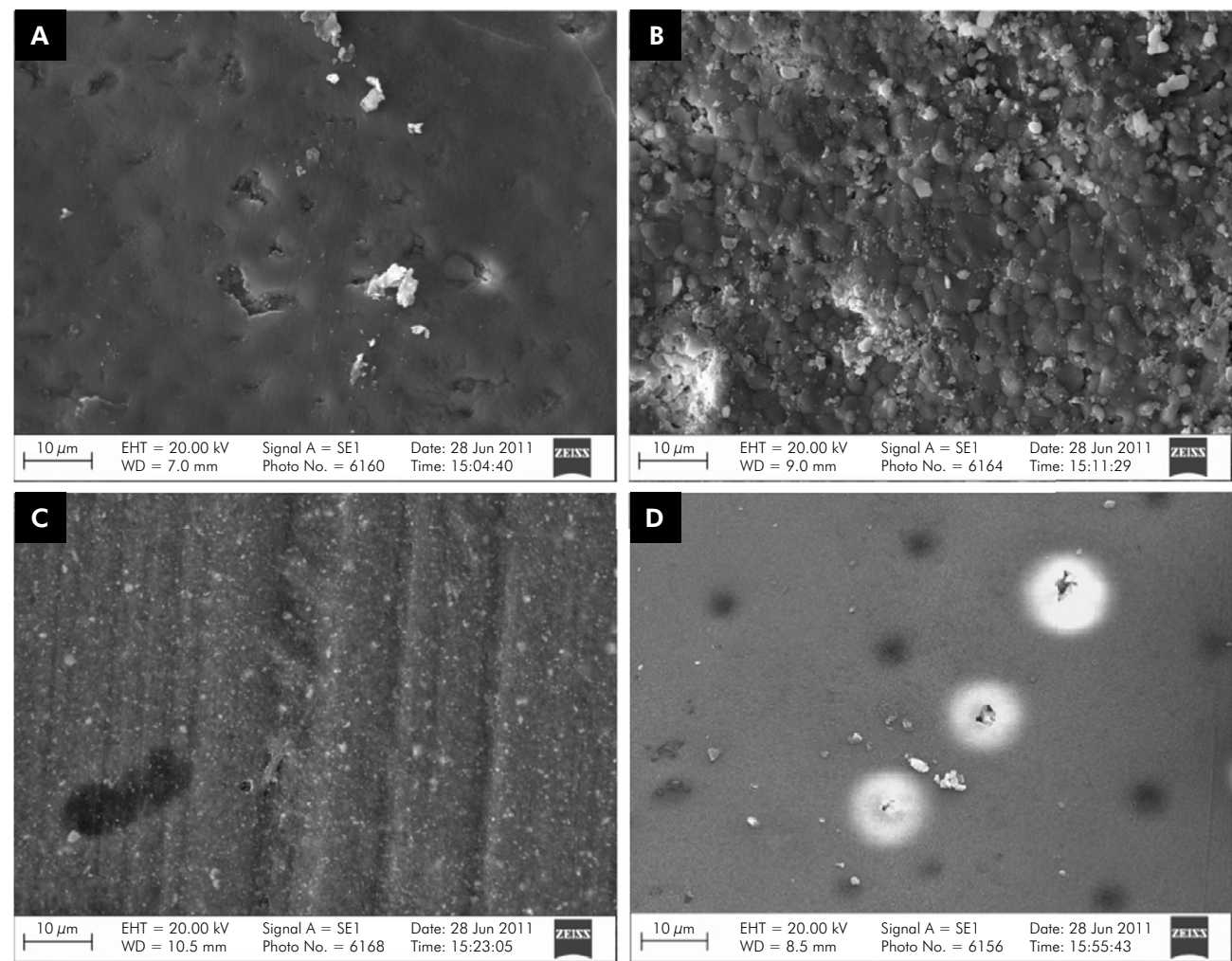

Figure 1. Baseline specimens without treatment: (A) enamel, (B) hydroxyapatite, (C) composite resin, and (D) ceramic (3,000 $\times)$
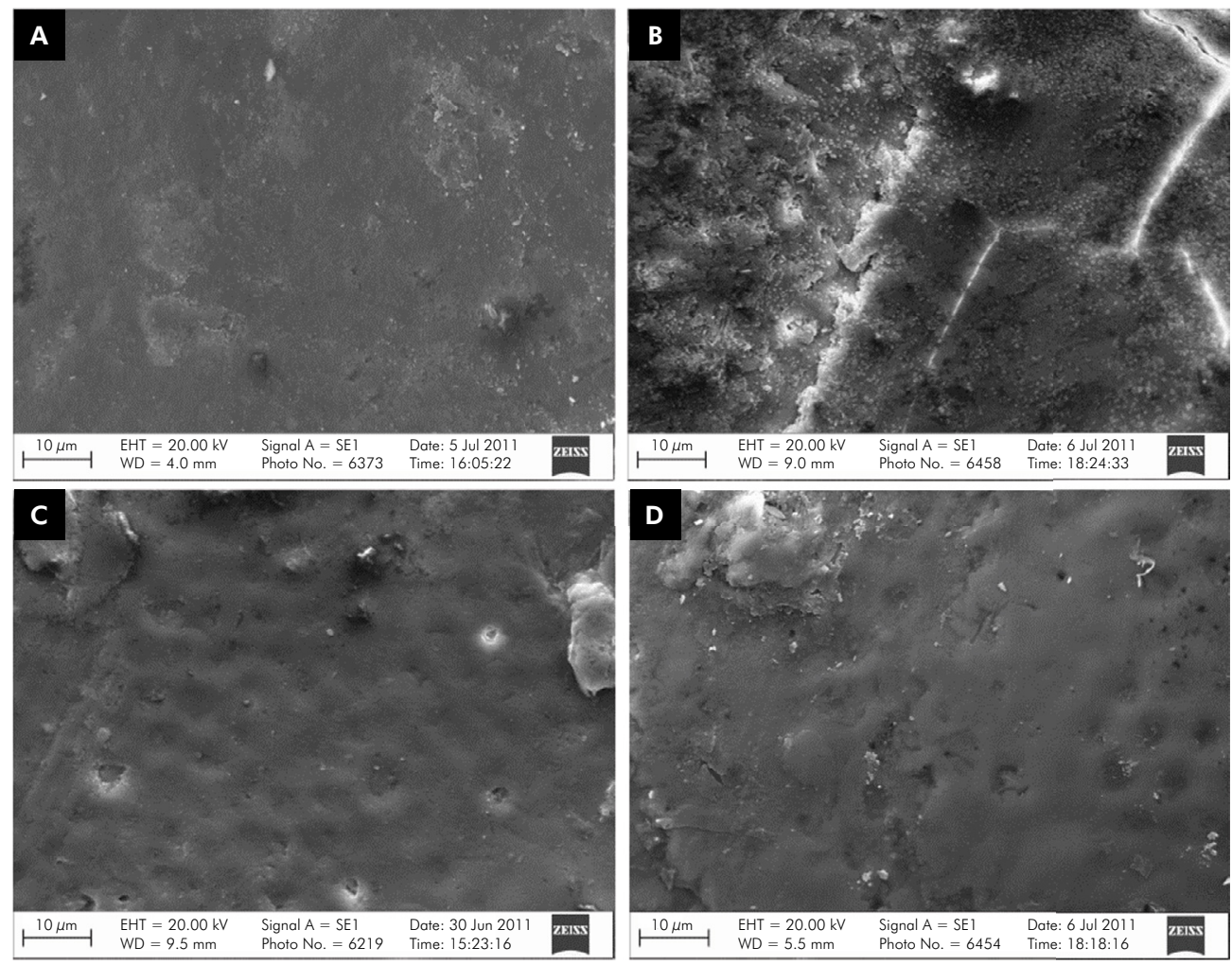

Figure 2. SEM images of enamel surfaces after each treatment period: (A) EO after 6 months, (B) EOFZC after 6 months, (C) $\mathrm{HP}$ after 3 months, and (D) $\mathrm{H}$ after 6 months $(3,000 \times)$. EO, essential oils mouthwash; EOFZC, essential oils + fluoride + zinc chloride mouthwash; $\mathrm{H}$, hydroalcohol control solution; $\mathrm{HP}$, hydrogen peroxide mouthwash; SEM, scanning electron microscope 

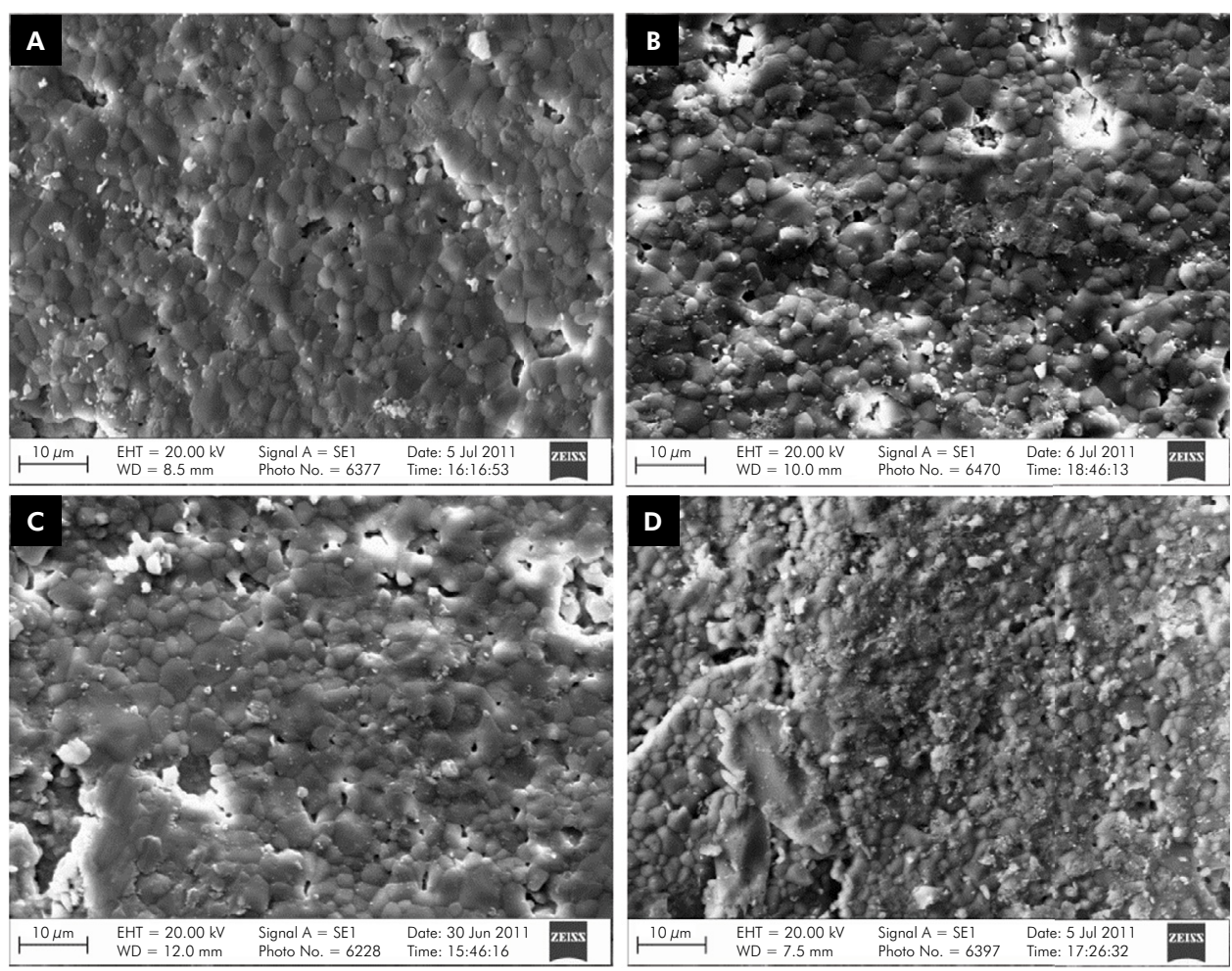

Figure 3. SEM images of hydroxyapatite surfaces after each treatment period: (A) EO after 6 months, (B) EOFZC after 6 months, (C) HP after 3 months, and (D) H after 6 months $(3,000 \times)$. EO, essential oils mouthwash; EOFZC, essential oils + fluoride + zinc chloride mouthwash; $\mathrm{H}$, hydroalcohol control solution; HP, hydrogen peroxide mouthwash; SEM, scanning electron microscope
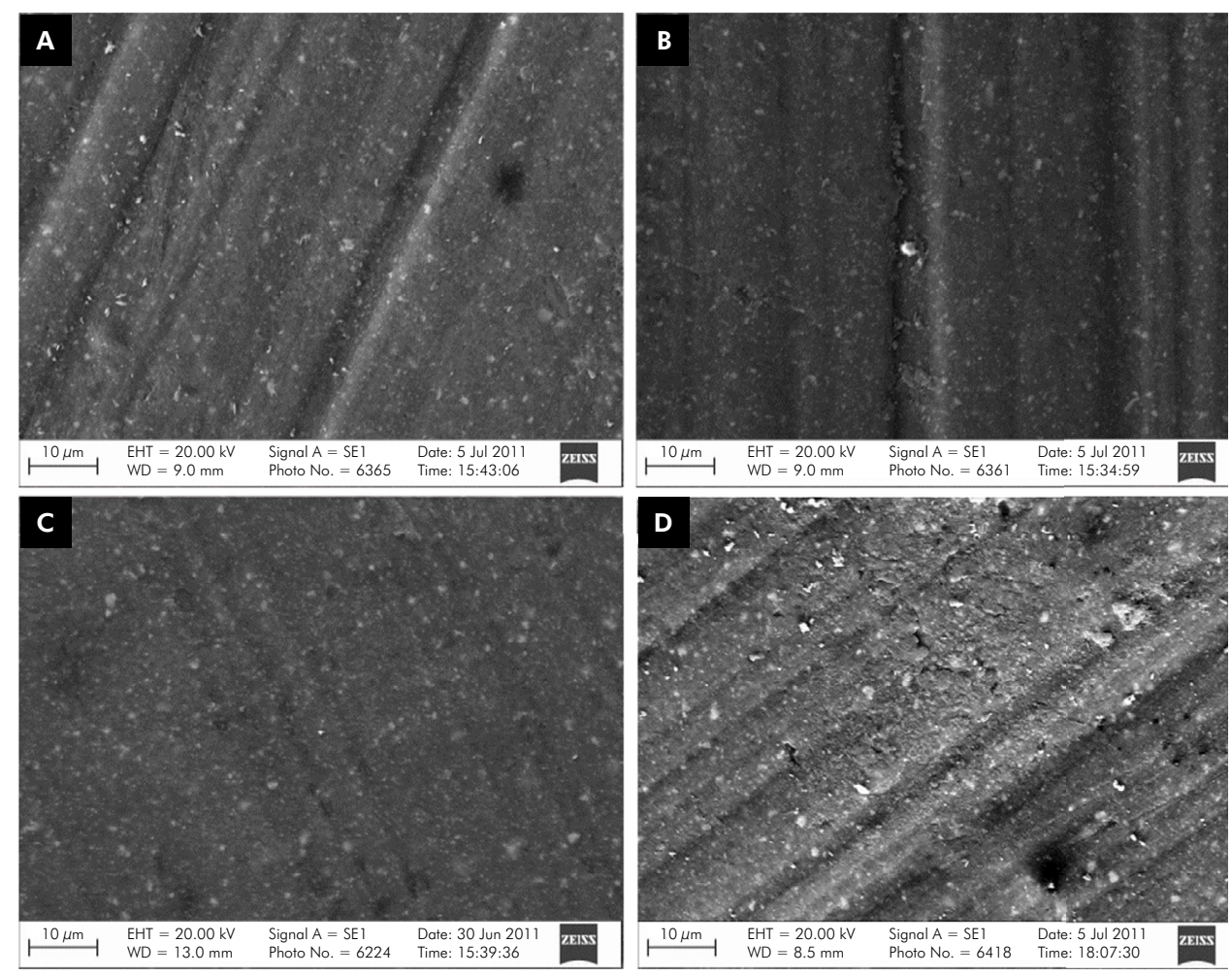

Figure 4. SEM images of composite resin surfaces after each treatment period: (A) EO after 6 months, (B) EOFZC after 6 months, (C) HP after 3 months, and (D) H after 6 months $(3,000 \times)$. EO, essential oils mouthwash; EOFZC, essential oils + fluoride + zinc chloride mouthwash; $\mathrm{H}$, hydroalcohol control solution; $\mathrm{HP}$, hydrogen peroxide mouthwash; SEM, scanning electron microscope 

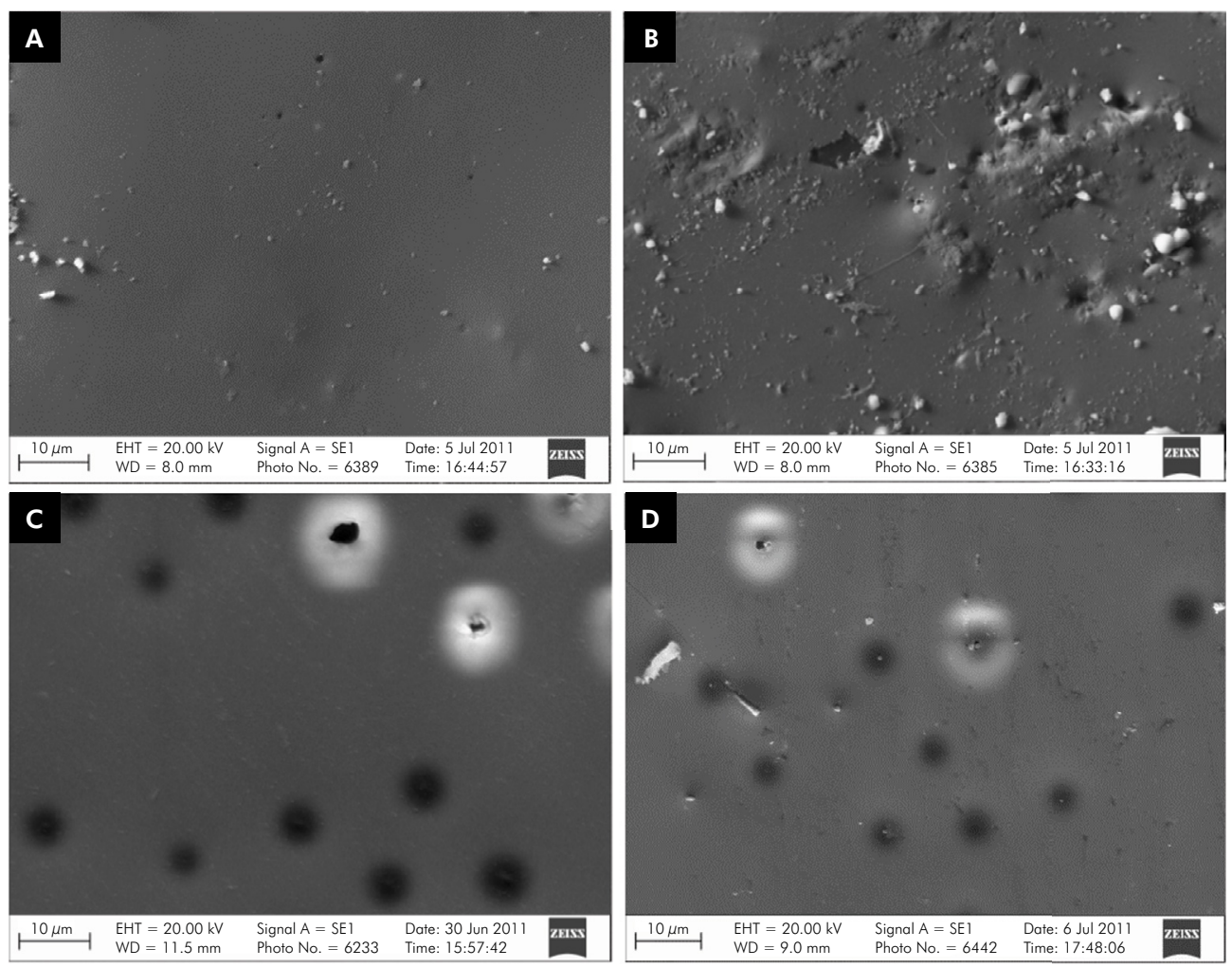

Figure 5. SEM images of ceramic surfaces after each treatment period: (A) EO after 6 months, (B) EOFZC after 6 months, (C) HP after 3 months, and (D) H after 6 months $(3,000 \times)$. EO, essential oils mouthwash; EOFZC, essential oils + fluoride + zinc chloride mouthwash; $\mathrm{H}$, hydroalcohol control solution; HP, hydrogen peroxide; SEM, scanning electron microscope

Table 5. Mean values for mineral elements in different surfaces and treatments obtained by EDX semi-quantitative mapping.

\begin{tabular}{|c|c|c|c|c|c|}
\hline \multirow{2}{*}{ Time point } & \multirow{2}{*}{ Treatment } & Enamel & Hydroxyapatite & Resin & Ceramic \\
\hline & & Ratio $(\mathrm{Ca}) /(\mathrm{P})$ & Ratio $(\mathrm{Ca}) /(\mathrm{P})$ & Ratio (Si)/(Ba) & Ratio (Si)/(Al) \\
\hline Baseline & NA & $1.82 \pm 0.13$ & $1.86 \pm 0.10$ & $2.05 \pm 0.28$ & $1.06 \pm 0.10$ \\
\hline 1 month & $\mathrm{HP}$ & $1.78 \pm 0.45$ & $1.87 \pm 0.11$ & $2.01 \pm 0.19$ & $1.05 \pm 0.11$ \\
\hline 3 months & $\mathrm{HP}$ & $1.82 \pm 0.01$ & $1.82 \pm 0.05$ & $1.96 \pm 0.03$ & $1.09 \pm 0.07$ \\
\hline 3 months & EO & $1.75 \pm 0.03$ & $1.83 \pm 0.07$ & $2.09 \pm 0.00$ & $1.08 \pm 0.13$ \\
\hline 3 months & EOFZC & $1.79 \pm 0.17$ & $1.81 \pm 0.05$ & $2.07 \pm 0.16$ & $1.11 \pm 0.12$ \\
\hline 3 months & $\mathrm{H}$ & $1.76 \pm 0.55$ & $1.84 \pm 0.14$ & $2.01 \pm 0.09$ & $1.10 \pm 0.10$ \\
\hline 6 months & EO & $1.76 \pm 0.20$ & $1.87 \pm 0.18$ & $2.03 \pm 0.19$ & $1.00 \pm 0.08$ \\
\hline 6 months & EOFZC & $1.75 \pm 0.27$ & $1.82 \pm 0.08$ & $2.07 \pm 0.12$ & $0.99 \pm 0.09$ \\
\hline 6 months & $\mathrm{H}$ & $1.75 \pm 0.06$ & $1.82 \pm 0.09$ & $2.00 \pm 0.15$ & $0.99 \pm 0.07$ \\
\hline
\end{tabular}

Note: Average obtained by surface mapping using $40 \times 1$ points with a step of $10 \mu \mathrm{m}$ along each sample until $1.0 \times 1.0 \mathrm{~mm}$. The average was compared by LS means and Student's t-tests and showed no significant variation.

$\mathrm{Al}=$ aluminum; $\mathrm{Ba}=$ barium; $\mathrm{Ca}=\mathrm{EDX}=$ energy-dispersive $\mathrm{X}$-ray spectroscopy, $\mathrm{EO}=$ essential oils mouthwash; $\mathrm{EOFZC}=$ essential oils + fluoride + zinc chloride mouthwash; $\mathrm{H}=$ hydroalcohol solution; $\mathrm{HP}=2.0 \%$ hydrogen peroxide mouthwash; $\mathrm{LS}=$ least squares.

in human enamel, hydroxyapatite, composite resin, and feldspathic ceramic surfaces under the experimental conditions simulating label directions. Furthermore, the samples tested did not undergo remineralization phases that are typically experienced in vivo. ${ }^{11} \mathrm{No}$ relevant change was seen as a result, although an overestimation of exposure time seemed likely.

Certain results from the present study are not consistent with findings from the available literature regarding the morphological and chemical stability as well 
Table 6. $\Delta \mathrm{E}^{*} \mathrm{ab}, \Delta \mathrm{L}$, and $\mathrm{L}^{*} \mathrm{a}^{*} \mathrm{~b}$ mean and standard deviation values $(\mathrm{n}=5)$.

\begin{tabular}{|c|c|c|c|c|c|c|c|}
\hline Time point & Treatment & Material & Luminosity (L*) & Red/Green $\left(a^{*}\right)$ & Yellow/Blue (b*) & $\Delta \mathrm{L}$ & $\Delta \mathrm{E}^{*} \mathrm{ab}$ \\
\hline \multirow{4}{*}{ Baseline } & \multirow{4}{*}{ No treatment } & Ceramic & $70.54( \pm 0.51)$ & $1.43( \pm 0.33)$ & $18.06( \pm 0.63)$ & & \\
\hline & & Enamel & $69.34( \pm 0.27)$ & $0.46( \pm 0.20)$ & $7.84( \pm 0.68)$ & & \\
\hline & & Hydroxyapatite & $89.25( \pm 0.64)$ & $0.35( \pm 0.15)$ & $1.67( \pm 0.12)$ & & \\
\hline & & Resin & $80.06( \pm 0.66)$ & $1.30( \pm 0.15)$ & $17.29( \pm 1.01)$ & & \\
\hline \multirow{4}{*}{1 month } & \multirow{4}{*}{$\mathrm{HP}$} & Ceramic & $70.37( \pm 0.94)$ & $1.36( \pm 0.23)$ & $18.36( \pm 0.41)$ & $-0.28( \pm 0.37)$ & $0.72( \pm 0.24)$ \\
\hline & & Enamel & $74.71( \pm 1.27)$ & $0.20( \pm 0.03)$ & $7.63( \pm 0.09)$ & $5.37( \pm 1.27)$ & $5.38( \pm 1.27)$ \\
\hline & & Hydroxyapatite & $89.40( \pm 0.12)$ & $0.39( \pm 0.20)$ & $1.63( \pm 0.12)$ & $0.07( \pm 0.12)$ & $0.23( \pm 0.15)$ \\
\hline & & Resin & $80.08( \pm 0.08)$ & $1.33( \pm 0.03)$ & $17.25( \pm 0.06)$ & $0.02( \pm 0.08)$ & $0.09( \pm 0.07)$ \\
\hline \multirow{4}{*}{3 months } & \multirow{4}{*}{$\mathrm{HP}$} & Ceramic & $70.63( \pm 0.44)$ & $1.45( \pm 0.07)$ & $18.25( \pm 0.19)$ & $0.09( \pm 0.44)$ & $0.46( \pm 0.15)$ \\
\hline & & Enamel & $76.80( \pm 0.70)$ & $0.17( \pm 0.05)$ & $6.96( \pm 0.47)$ & $7.53( \pm 0.75)$ & $7.46( \pm 0.70)$ \\
\hline & & Hydroxyapatite & $89.14( \pm 0.29)$ & $0.54( \pm 0.16)$ & $2.12( \pm 0.33)$ & $-0.18( \pm 0.29)$ & $0.63( \pm 0.20)$ \\
\hline & & Resin & $79.69( \pm 0.05)$ & $1.28( \pm 0.04)$ & $17.21( \pm 0.49)$ & $-0.37( \pm 0.05)$ & $0.56( \pm 0.16)$ \\
\hline \multirow{4}{*}{3 months } & \multirow{4}{*}{$\mathrm{EO}$} & Ceramic & $70.93( \pm 1.70)$ & $1.20( \pm 0.11)$ & $18.36( \pm 0.32)$ & $0.40( \pm 1.70)$ & $1.42( \pm 0.93)$ \\
\hline & & Enamel & $70.76( \pm 0.64)$ & $0.28( \pm 0.07)$ & $8.29( \pm 0.05)$ & $1.42( \pm 0.64)$ & $1.51( \pm 0.61)$ \\
\hline & & Hydroxyapatite & $89.08( \pm 0.23)$ & $0.42( \pm 0.01)$ & $2.44( \pm 0.18)$ & $-0.17( \pm 0.23)$ & $0.81( \pm 0.23)$ \\
\hline & & Resin & $78.58( \pm 1.12)$ & $1.25( \pm 0.14)$ & $16.56( \pm 0.61)$ & $-1.48( \pm 1.12)$ & $1.67( \pm 1.67)$ \\
\hline \multirow{4}{*}{3 months } & \multirow{4}{*}{ EOFZC } & Ceramic & $70.65( \pm 1.00)$ & $1.17( \pm 0.29)$ & $18.17( \pm 1.33)$ & $-0.22( \pm 0.78)$ & $1.19( \pm 0.14)$ \\
\hline & & Enamel & $72.82( \pm 0.79)$ & $0.28( \pm 0.09)$ & $9.33( \pm 0.09)$ & $3.20( \pm 0.56)$ & $3.56( \pm 0.47)$ \\
\hline & & Hydroxyapatite & $88.76( \pm 0.15)$ & $0.42( \pm 0.02)$ & $2.42( \pm 0.17)$ & $-0.49( \pm 0.15)$ & $0.90( \pm 0.21)$ \\
\hline & & Resin & $79.70( \pm 0.57)$ & $0.63( \pm 0.10)$ & $15.96( \pm 0.42)$ & $-0.36( \pm 0.57)$ & $1.61( \pm 0.43)$ \\
\hline \multirow{4}{*}{3 months } & \multirow{4}{*}{$\mathrm{H}$} & Ceramic & $70.23( \pm 1.13)$ & $1.32( \pm 0.36)$ & $18.40( \pm 1.56)$ & $-0.30( \pm 1.13)$ & $1.55( \pm 1.06)$ \\
\hline & & Enamel & $70.48( \pm 0.78)$ & $0.11( \pm 0.06)$ & $9.83( \pm 0.08)$ & $1.14( \pm 0.78)$ & $2.42( \pm 0.31)$ \\
\hline & & Hydroxyapatite & $88.14( \pm 0.62)$ & $0.43( \pm 0.02)$ & $2.27( \pm 0.06)$ & $-1.12( \pm 0.62)$ & $1.31( \pm 0.52)$ \\
\hline & & Resin & $77.70( \pm 0.60)$ & $0.89( \pm 0.02)$ & $16.08( \pm 0.28)$ & $-2.36( \pm 0.60)$ & $2.69( \pm 0.66)$ \\
\hline \multirow{4}{*}{6 months } & \multirow{4}{*}{$\mathrm{EO}$} & Ceramic & $70.23( \pm 0.51)$ & $1.31( \pm 0.14)$ & $18.23( \pm 0.62)$ & $-0.31( \pm 0.51)$ & $0.78( \pm 0.27)$ \\
\hline & & Enamel & $72.13( \pm 0.72)$ & $0.32( \pm 0.03)$ & $8.31( \pm 0.06)$ & $2.79( \pm 0.72)$ & $2.84( \pm 072)$ \\
\hline & & Hydroxyapatite & $89.03( \pm 0.18)$ & $0.42( \pm 0.02)$ & $2.40( \pm 0.17)$ & $-0.22( \pm 0.18)$ & $0.78( \pm 0.21)$ \\
\hline & & Resin & $79.30( \pm 0.40)$ & $1.71( \pm 0.06)$ & $16.16( \pm 0.08)$ & $-0.76( \pm 0.40)$ & $1.45( \pm 0.27)$ \\
\hline \multirow{4}{*}{6 months } & \multirow{4}{*}{ EOFZC } & Ceramic & $70.61( \pm 0.54)$ & $1.43( \pm 0.14)$ & $18.96( \pm 0.67)$ & $0.07( \pm 0.54)$ & $1.04( \pm 0.67)$ \\
\hline & & Enamel & $73.11( \pm 0.92)$ & $0.28( \pm 0.07)$ & $9.31( \pm 0.07)$ & $3.44( \pm 0.61)$ & $3.76( \pm 0.53)$ \\
\hline & & Hydroxyapatite & $88.80( \pm 0.04)$ & $0.42( \pm 0.02)$ & $2.31( \pm 0.02)$ & $-0.45( \pm 0.04)$ & $0.79( \pm 0.04)$ \\
\hline & & Resin & $79.73( \pm 0.56)$ & $0.71( \pm 0.11)$ & $16.16( \pm 0.18)$ & $-0.33( \pm 0.56)$ & $1.42( \pm 0.09)$ \\
\hline \multirow{4}{*}{6 months } & \multirow{4}{*}{$\mathrm{H}$} & Ceramic & $70.00( \pm 0.78)$ & $1.20( \pm 0.23)$ & $17.89( \pm 1.01)$ & $-0.54( \pm 0.78)$ & $1.20( \pm 0.59)$ \\
\hline & & Enamel & $71.51( \pm 0.91)$ & $0.29( \pm 0.36)$ & $9.75( \pm 0.16)$ & $2.17( \pm 0.91)$ & $2.98( \pm 0.64)$ \\
\hline & & Hydroxyapatite & $88.09( \pm 0.41)$ & $0.44( \pm 0.04)$ & $2.26( \pm 0.04)$ & $-1.16( \pm 0.41)$ & $1.33( \pm 0.33)$ \\
\hline & & Resin & $77.60( \pm 0.55)$ & $0.89( \pm 0.05)$ & $16.08( \pm 0.27)$ & $-2.47( \pm 0.55)$ & $2.78( \pm 0.62)$ \\
\hline
\end{tabular}

$\mathrm{EO}=$ essential oils mouthwash; EOFZC = essential oils + fluoride + zinc chloride mouthwash; $\mathrm{H}=$ hydroalcohol solution; $\mathrm{HP}=2.0 \%$

hydrogen peroxide mouthwash.

as durability of surfaces after using alcohol-containing mouthwashes. The literature on the detrimental effect or lack of effect of EO alcohol-containing mouthwashes on microhardness $(\mathrm{SMH}),{ }^{12,13}$ surface roughness, ${ }^{13,14}$ surface strength, ${ }^{15}$ fluid absorption, ${ }^{16,17}$ color stability, $1,1,7,18,19,20$ and wear ${ }^{12}$ of direct restorative materials have demonstrated that these findings were dependent on the type of material used, study design, and analytical methodology. It is well established that saliva provides protection against caries. Inclusion of artificial saliva in this study therefore increases the clinical relevance of the results. ${ }^{21,22}$
Several published in vitro studies have detailed the detrimental effects or lack of effect of peroxide-containing tooth whitening products on enamel microhardness, enamel resistance to abrasion, dentin microhardness, dentin roughening, and restoration microhardness. ${ }^{23,24,25}$ The results are also based on the methodology used and the tested materials or products. Numerous recent studies have indicated that hydrogen peroxide- and carbamide peroxide-containing products confer no remarkable deleterious effects on SMH of human enamel and dentin. 13,18 
According to studies, small chemical and elemental alterations from EO alcohol-containing mouthwashes in human enamel, ceramic, and hydroxyapatite can occur; therefore, it is important to consider the clinical relevance of this study on the daily use of mouthwashes and its implications on safety, durability, and esthetic aspects. The anticalculus effect of an EO-containing zinc chloride formulation was previously evaluated using X-ray diffraction, infrared spectroscopy, and SEM. ${ }^{26}$ The present study evaluated only the inorganic components of human dental calculus and the ability to inhibit calculus formation.

Degradation of restorative materials can occur because of chemical and mechanical factors from the oral environment, which may lead to changes on surfaces ${ }^{27,28}$ as well as on composite resin characteristics. ${ }^{16}$ This degradation not only affects the esthetics but can also facilitate an increase of plaque buildup, inflammation, and recurrent caries. ${ }^{29}$ In the present study, no relevant morphologic, elemental, or chemical change was observed on composite resin surfaces during the examination periods. The ceramic surfaces showed minor changes, under $3,000 \times$ magnification, wherein certain erosions were observed. New analyses revealed that the erosions were present before the treatment and were thus mostly caused by factors such as the quality and preparation of the ceramic material. A superficial change was observed on the human enamel surface at 1 month after the use of whitening mouthwash, which was reversed after 3 months of use. This may have been due to the remineralizing effect of the artificial saliva used as storage solution.

CIE L*a* ${ }^{*}$ analysis was used to evaluate changes in color stability $(\Delta \mathrm{E})$. No alteration was detected in the color properties of the composite resins, with similar results to certain studies..$^{15,17-20}$ The effects of peroxide bleaching on the surface texture and chemistry of the restoration are strongly dependent on the type of restoration..$^{30}$ Overall, a composite restoration seems to be more reactive to the effects of bleaching. ${ }^{23,31}$

Regarding surface staining, studies have reported ${ }^{31,32,33,34,35}$ that $\Delta \mathrm{E}$ values $>3.3$ are clinically unacceptable. The present study showed $\Delta \mathrm{E}$ mean values of 1.72 and 2.03 for LISTERINE ${ }^{\circledR}$ Cool Mint $^{\circledR}$ and LISTERINE ${ }^{\circledR}$ Total Care, respectively, 0.70 for composite resin and 1.40 for ceramic restorations by simulating 6 months of daily use. LISTERINE $^{\circledR}$ Whitening showed $\triangle \mathrm{E}$ mean values of 1.28 for composite resin and 0.78 for ceramic at 3 months, suggesting its safety and color stability for restorative materials under experimental conditions. The only relevant colorimetric change was a whitening effect on the enamel surface with LISTERINE ${ }^{\circledR}$ Whitening due to its hydrogen peroxide content after simulating 12 weeks of daily use, which is in agreement with findings from the available literature. ${ }^{24,25}$

\section{Conclusion}

Results of this in vitro study show that the ultrastructure and morphology of enamel and dental restorative materials did not present any meaningful change with any of the mouthwash treatments after up to 6 months of simulated daily use. No variation in either relative $\mathrm{Ca}$ or $\mathrm{P}$ concentrations of enamel, $\mathrm{Si}$ and Ba concentrations of composite resin, or $\mathrm{Si}$ and $\mathrm{Al}$ concentrations of ceramic were observed before and after all treatments. No change was detected in the biochemical and color properties of any of the specimens except the whitening rinse, which had a whitening effect on enamel surfaces. Longterm exposure of these alcohol-containing, low $\mathrm{pH}$ mouthwashes $(<5.5)$ caused no ultra-structural and biochemical change on human enamel and restorative materials.

\section{Acknowledgments}

The authors would like to acknowledge the editorial support and publication management conducted by Jane Zhang, PhD and Jessica Lewis, PharmD from Johnson and Johnson Consumer Inc. Scientific writing support including editing, assembling tables, creating high-resolution images based on authors' detailed directions, organizing author comments, fact-checking, and referencing was provided by Cactus Communications and funded by Johnson \& Johnson Consumer Inc. 


\section{References}

1. Boyle P, Koechlin A, Autier P. Mouthwash use and the prevention of plaque, gingivitis and caries. Oral Dis. 2014 Jan;20 Suppl 1:1-68. https://doi.org/10.1111/odi.12187

2. Lindhe J, Westfelt E, Nyman S, Socransky SS, Haffajee AD. Long-term effect of surgical/non-surgical treatment of periodontal disease. J Clin Periodontol. 1984 Aug;11(7):448-58. https://doi.org/10.1111/j.1600-051X.1984.tb01344.x

3. Lavstedt S, Modéer T, Welander E. Plaque and gingivitis in a group of Swedish schoolchildren with special reference to toothbrushing habits. Acta Odontol Scand. 1982;40(5):307-11. https://doi.org/10.3109/00016358209024074

4. Gjermo P, Rösing CK, Susin C, Oppermann R. Periodontal diseases in Central and South America. Periodontol 2000. 2002;29(1):70-8. https://doi.org/10.1034/j.1600-0757.2001.290104.x

5. Addy M, Moran JM. Evaluation of oral hygiene products: science is true; don't be misled by the facts. Periodontol 2000. 1997 Oct;15(1):40-51. https://doi.org/10.1111/j.1600-0757.1997.tb00103.x

6. Sharma N, Charles CH, Lynch MC, Qaqish J, McGuire JA, Galustians JG et al. Adjunctive benefit of an essential oil-containing mouthrinse in reducing plaque and gingivitis in patients who brush and floss regularly: a six-month study. J Am Dent Assoc. 2004 Apr;135(4):496-504. https://doi.org/10.14219/jada.archive.2004.0217

7. Araujo MW, Charles CA, Weinstein RB, McGuire JA, Parikh-Das AM, Du Q et al. Meta-analysis of the effect of an essential oil-containing mouthrinse on gingivitis and plaque. J Am Dent Assoc. 2015 Aug;146(8):610-22. https://doi.org/10.1016/i.adaj.2015.02.011

8. Pretty IA, Edgar WM, Higham SM. The erosive potential of commercially available mouthrinses on enamel as measured by Quantitative Light-induced Fluorescence (QLF). J Dent. 2003 Jul;31(5):313-9. https://doi.org/10.1016/\$0300-5712(03)00067-8

9. Corso S, Corso AC, Hugo FN, Padilha DM. Evaluation of the erosive potential of oral mouthwashes. Rev Odonto Cienc. 2004;19:233-7.

10. DePaola LG, Eschenaur Spolarich A. Safety and efficacy of antimicrobial mouth rinses in clinical practice. J Dent Hyg. 2007;81(suppl 1):1-16.

11. Moreno EC, Zahradnik RT. Demineralization and remineralization of dental enamel. J Dent Res. 1979 Mar;58(Spec Issue B Supplement 2):896-903. https://doi.org/10.1177/00220345790580024301

12. Yap AU, Tan BW, Tay LC, Chang KM, Loy TK, Mok BY. Effect of mouthrinses on microhardness and wear of composite and compomer restoratives. Oper Dent. 2003 Nov-Dec;28(6):740-6.

13. Festuccia MS, Garcia LF, Cruvinel DR, Pires-DeSouza FC. Color stability, surface roughness and microhardness of composites submitted to mouthrinsing action. J Appl Oral Sci. 2012 Mar-Apr;20(2):200-5 https://doi.org/10.1590/S1678-77572012000200013

14. Sadaghiani L, Wilson MA, Wilson NH. Effect of selected mouthwashes on the surface roughness of resin modified glassionomer restorative materials. Dent Mater. 2007 Mar;23(3):32534. https://doi.org/10.1016/i.dental.2006.01.024

15. Von Fraunhofer JA, Kelley JI, De Paola LG, Meiller TF. The effect of a mouth rinse containing essential oils on dental restorative materials. Oper Dent. 2006;403-7.

16. Almeida GS, Poskus LT, Guimarães JG, da Silva EM. The effect of mouthrinses on salivary sorption, solubility and surface degradation of a nanofilled and a hybrid resin composite. Oper Dent. 2010 Jan-Feb;35(1):105-11. https://doi.org/10.2341/09-080-L

17. Celik C, Yuzugullu B, Erkut S, Yamanel K. Effects of mouth rinses on color stability of resin composites. Eur J Dent. 2008 Oct;2(4):247-53.

18. Gurgan S, Yalcin Cakir F. The effect of three different mouthrinses on the surface hardness, gloss and colour change of bleached nano composite resins. Eur J Prosthodont Restor Dent. 2008 Sep;16(3):104-8.

19. Lee YK, El Zawahry M, Noaman KM, Powers JM. Effect of mouthwash and accelerated aging on the color stability of esthetic restorative materials. Am J Dent. 2000 Jun;13(3):159-61.

20. Addy M, Mahdavi SA, Loyn T. Dietary staining in vitro by mouthrinses as a comparative measure of antiseptic activity and predictor of staining in vivo. J Dent. 1995 Apr;23(2):95-9. https://doi.org/10.1016/0300-5712(95)98974-8

21. Humphrey SP, Williamson RT. A review of saliva: normal composition, flow, and function. J Prosthet Dent. 2001 Feb;85(2):162-9. https://doi.org/10.1067/mpr.2001.113778

22. Hellwig E, Lussi A, Goetz F. Influence of human saliva on the development of artificial erosions. Caries Res. 2013;47(6):553-8. https://doi.org/10.1159/000351634

23. Nathoo SA, Chmielewski MB, Kirkup RE. Effects of Colgate Platinum Professional Tooth Whitening System on microhardness of enamel, dentin, and composite resins. Compend Contin Educ Dent Suppl. 1994;17:S627-30.

24. Torres CR, Perote LC, Gutierrez NC, Pucci CR, Borges $A B$. Efficacy of mouth rinses and toothpaste on tooth whitening. Oper Dent. 2013 Jan-Feb;38(1):57-62. https://doi.org/10.2341/11-360-L

25. Douglas A, Engelman E, Wu M, Moore M, Ricci-Nittel D, Mordas CJ. In-vitro intrinsic whitening efficacy of a peroxide and fluoridecontaining mouth rinse. J Dent Res. 1992;92 Abstract 1296.

26. LeGeros RZ, Rohanizadeh R, Lin S, Mijares D, LeGeros JP, Charles $\mathrm{CH}$ et al. Dental calculus composition following use of essential-oil/ZnCl2 mouthrinse. Am J Dent. 2003 Jun;16(3):155-60. 
In vitro effects of alcohol-containing mouthwashes on human enamel and restorative materials

27. Moraes RR, Ribeiro DS, Klumb MM, Brandt WC, Correr-Sobrinho L, Bueno M. In vitro toothbrushing abrasion of dental resin composites: packable, microhybrid, nanohybrid and microfilled materials. Braz Oral Res. 2008 Apr-Jun;22(2):112-8. https://doi.org/10.1590/S1806-83242008000200004

28. Voltarelli FR, Santos-Daroz CB, Alves MC, Cavalcanti AN, Marchi GM. Effect of chemical degradation followed by toothbrushing on the surface roughness of restorative composites. J Appl Oral Sci. 2010 Dec;18(6):585-90. https://doi.org/10.1590/S1678-77572010000600009

29. Bollen CM, Lambrechts P, Quirynen M. Comparison of surface roughness of oral hard materials to the threshold surface roughness for bacterial plaque retention: a review of the literature. Dent Mater. $1997 \mathrm{Jul} ; 13(4): 258-69$. https://doi.org/10.1016/S0109-5641(97)80038-3

30. 30. Khokhar ZA, Razzoog ME, Yaman P. Color stability of restorative resins. Quintessence Int. 1991 Sep;22(9):733-7.
31. Ruyter IE, Nilner K, Moller B. Color stability of dental composite resin materials for crown and bridge veneers. Dent Mater. 1987 Oct;3(5):246-51. https://doi.org/10.1016/S0109-5641(87)80081-7

32. Gürdal P, Akdeniz BG, Hakan Sen B. The effects of mouthrinses on microhardness and colour stability of aesthetic restorative materials. J Oral Rehabil. 2002 Sep;29(9):895-901. https://doi.org/10.1046/j.1365-2842.2002.00924.x

33. Swift EJ Jr, Perdigão J. Effects of bleaching on teeth and restorations. Compend Contin Educ Dent. 1998 Aug;19(8):81520.

34. Schenk-Meuster K, Duschner H, Kozak KM, Götz H, Zoladz JR, White DJ. Dental restoration curing: effects of bleaches on tomography and microhardness. J Dent Res. 2002 Mar;81(1 suppl A):3433.

35. Villalta P, Lu H, Okte Z, Garcia-Godoy F, Powers JM. Effects of staining and bleaching on color change of dental composite resins. J Prosthet Dent. 2006 Feb;95(2):137-42. https://doi.org/10.1016/i.prosdent.2005.11.019 